\title{
Quantifying and Monitoring Ecological Response to No-Take Marine Reserves
}

\author{
Jason Krumholz (Corresponding author) \\ Graduate School of Oceanography, University of Rhode Island \\ South Ferry Rd. Narragansett, RI 02882, United States \\ Tel: 1-401-874-6011Ｅ-mail: jkrumholz@gso.uri.edu
}

Received: June 2, 2011 Accepted: July 10, 2011 doi:10.5296/jee.v2i1.696

\begin{abstract}
The primary goal of the paper is to review techniques for measuring ecosystem response and determining if a no-take reserve can meet natural resource conservation or fisheries management goals. Recently, the increasing role of MPAs in the management of coastal resources, has prompted increased consideration of MPAs in the northeast US. The paper also considers methods associated with reserve design, and monitoring. This paper recommends that traditional sampling and monitoring methods be integrated with more recently developed methodology, and reviews successful and unsuccessful marine reserve applications of techniques such as Geographical Information Systems (GIS), Indexes of Biotic Integrity (IBI), and indicator species assessments, as well as commenting on the use of simple and spatially explicit models in a reserve context.
\end{abstract}

Keywords: MPA, Monitoring, Marine reserves, Ecological response, Fisheries 


\section{Introduction and Background}

The concept of using reserves, areas set aside where usage and extraction of natural resources is restricted, as a management tool in terrestrial systems has been in place for over a century. However, the application of this management strategy to marine habitats has only come into widespread use over the last few decades, as a means to protect marine natural and cultural resources, and as a fisheries management tool (Bohnsack, 2006; Roberts et al, 2001). Marine reserves, also referred to as Marine Protected Areas (MPAs), have been shown to increase size, total biomass, fecundity, and recruitment in fish (Palumbi, 2002; Halpern and Warner, 2002; Fujita 2003). Reserves have also been linked to preservation and restoration of depleted fisheries through spillover effects and larval dispersal (Roberts et al., 2001; Ami et al., 2005; Palumbi, 2002). Some evidence suggests that reserves may help provide resistance against invasive species, conserve critical habitats, increasediversity, and improve ecosystem status (Stachowitz et al., 1999; Palumbi, 2002; Giangrande et al., 2005; Graham et al., 2011).

However, the ability of reserves to cope with external anthropogenic sources of impact has been called into question (Jameson et al., 2002; Shipp, 2002), which could limit their ability as a conservation tool. Furthermore, reserves do not always accomplish their conservation goals (Halpern and Warner, 2002; Cote et al., 2001), and are often criticized as an ineffective tool from a fisheries perspective (Hanneson, 1998; Roberts and Sargant, 2002; Shipp, 2002). In addition, the effect of reserves on ecosystem based management efforts has been debated, as trophic cascades in reserves have been linked to unexpected effects at lower trophic levels (Jennings and Polunin, 1997; Pinnegar et al., 2000; Ashworth and Ormond, 2005). Therefore, it is critically important to develop and implement experimental programs to predict and monitor the effectiveness of a proposed reserve to determine if a reserve is the most effective management strategy for a given situation.

The role of MPAs in protecting marine resources in the United States was enhanced in 2000, with passage of Presidential Executive Order 13158. This document was designed to "strengthen the management, protection, and conservation of existing marine protected areas and develop a scientifically based, comprehensive national system of MPAs” (Federal Register, 2000). Executive order 13158 presents a broad definition for marine reserves, and frequently in the literature, terminology such as marine reserve, MPA, and Marine Park are used interchangeably to refer to any marine area with restrictions on activity. However, there are many different specific types of marine reserves or MPAs (Table 1). This paper deals primarily with reserves where extraction of marine resources is prohibited year round. For consistency purposes, when this level of protection is specified, the terminology "no-take reserve" will be used. Year round permanent no-take reserves have been used extensively in tropical settings around the world, not only as a primary natural resource conservation tool to protect coral reef ecosystems, but also as a tool for sustainable fisheries yield(e.g. Graham et al., 2011; Almany et al., 2007). Recently, there has been a dramatic increase in the number of permanent year round closures in temperate environments, such as Europe and the west coast of North America; however, there are no major reserves that meet these criteria in the northeast coastal United States (although many small scale reserves and reserves with partial protection; such as the National Estuarine Research Reserves do exist). Therefore, this 
document draws heavily on research conducted on reserves in similar temperate regions, while also considering applicable techniques from tropical marine reserves.

Table 1. National MPA center classification system for marine reservesa
(a) Primary Conservation Focus (3)
(b) Level of Protection Afforded (6)
(1) Natural Heritage
INo Access
(1) Cutural Heritage
¿No Impact
[1] Sustainable Production
口No Take
(1) Zoned With No Take Area(s)
D Zoned Multiple Use
I Uniform Multiple Use
(c) Permanence of Protection (3)
Dermanent
Ð Conditional
$\square$ Temporary
(e) Ecological Scale of Protection (2)
D Ecosystem
】 Focal Resoutce

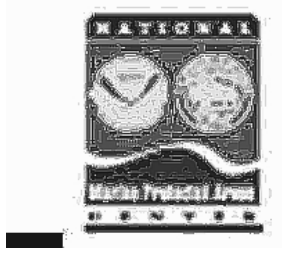
(d) Constancy of Protection (3)
$\square$ Year-round
$\square$ Seasona1
$\square$ Rotating

Table 1 adapted from www.mpa.org, MPA Center two-tiered classification system for Marine Protected Areas. First tier categories are highlighted. Under the MPA Center system, this document primarily concerns itself with the effects of permanent year-round no-take natural heritage reserves.

The purpose of this paper is to review scientific methods of determining whether a no-take reserve is the most effective tool to accomplish management goals in the northeastern US. To do this effectively, techniques must quantify the ecological response to the establishment of no-take reserves, and should help coastal managers design a program of study for conservation, fisheries, and natural heritage goals. To that end, the paper considers scientific methods in key areas where science plays a role in reserve management. The primary focus of this paper is on methods of detecting ecosystem response to reserve implementation. The secondary objectives of this report include discussion of the scientific methods associated with reserve design, monitoring, and quantifying fisheries (finfish and shellfish) response. The findings presented in this paper can be applied broadly, but are focused on the Northeast US. Within the coastal Northeast, research is warranted to demonstrate if a reserve or network of reserves would be an effective tool to accomplish an area's conservation, restoration, and/or fisheries goals.

\section{Site Selection}

Location can play a critical role in reserve effectiveness. However, while science plays a role in determining the best location for the establishment of reserves, it is important to recognize the role of socioeconomic processes in determining a reserve site. Stakeholder involvement processes associated with reserve generation are extensive and often contentious. As an early 
reviewer of this manuscript noted; "managing an MPA is not about managing the environment, it is about managing human behavior towards and within the environment". This paper acknowledges the fundamental importance of stakeholder involvement in the overall process, but focuses on scientific processes for identifying ideal reserve size and location.

\subsection{Habitat Conservation}

MPA literature refers frequently to the protection of "critical habitat." A functional working definition of critical habitat is "any habitat essential to the conservation of target species (e.g. spawning or nursery grounds), or habitat requiring preservation or restoration for natural heritage purposes (e.g. seagrass meadows).” Thus, the definition of critical habitat depends heavily on the goals of the reserve. Identifying areas where critical habitat is present can often be done using pre-existing data, both scientific and anecdotal (interviews, logbooks, etc.), but may require shipboard or aerial surveys. Once habitat data are collected, reserve design task forces are relying increasingly on GIS based tools to combine many layers of data from scientific, fisheries, and anecdotal sources. OceanMap is one such tool which integrates ecological and socioeconomic data obtained by interviewing knowledgeable locals (e.g. fishermen) with scientific and fisheries data to generate a GIS database that can be used to identify priority areas for conservation (Scholtz et al., 2004; Fujita, 2003). GIS based tools can also be used to aid in the evaluation of MPA efficacy (Friedlander et al., 2007;Chape et al., 2005; see sections 3\&4 below).

In some cases (e.g. eelgrass meadows), it is relatively straightforward to identify present coverage, but somewhat more complex to identify areas that would be suitable sites for restoration. Modern techniques such as sediment profile imaging (SPI) (Bradley \& Stolt, 2006) and high resolution sidescan sonar (Degraer et al., 2008) can be coupled with traditional methods like light and nutrient measurements to accurately categorize temperature regimes, bottom types, sediment parameters and locations most suitable for restoration efforts and identify biological hotspots (Dennison et al. 1993; Bradley \& Stolt, 2006).

\subsection{Sizing and Placement}

Data from around the world show that positive benefits can be seen from no-take reserves as small as $1 \mathrm{~km}^{2}$ (Halpern, 2003; Halpern, 2002), but most estimations of the minimum necessary reserve size range from about $10 \%$ of the overall habitat area to $40-50 \%$ of the total area, as either a single reserve, or a network of smaller reserves (Sala et al., 2002; Hastings \& Botford, 1999; Halpern, 2003; NRC, 2001). Single large reserves are easier to enforce, and are better for large or mobile species, but networks of smaller reserves may have better results for habitat conservation, larval dispersal, and protection of sessile species (Polackcheck, 1990; Halpern and Warner, 2003; Planes et al., 2008). The high amount of variation in these estimates is due in part to the wide range of models used, but in addition to the range of locations and goals. Many of the higher estimates come from temperate areas, such as California's Channel Islands, and from reserves that are designed to protect large or highly mobile species (Sala et al. 2002; Halpern \& Warner, 2003; Cowie-Haskell \& Delaney, 2003). Literature also suggests that a network of smaller reserves of approximately $50-75 \mathrm{~km}^{2}$ 
(20-30\% of overall area) might be appropriate (Halpern and Warner, 2003; Sala et al., 2002).

Modeling provides a low cost synthetic approach to solving problems in ecology, and a wide range of models are used in the reserve siting process. One example by Sala et al. (2002) uses optimization algorithms and a canonical correspondence analysis (CCA) to identify the best sites. The model was built for the Gulf of California, and uses three conservation goals: the protection of a certain amount of every habitat type; protection of a higher percentage of rare or critical habitats; and sufficient continuity of reserve parcels to permit larval dispersal. The overall goal of protecting diversity is enhanced by the CCA, which identifies environmental parameters associated with species richness, and weights the optimization algorithms toward protection of areas with highest diversity. This model could be adapted for use in estuaries and coastal areas of the northeast (Table 2). Sala et al. (2002) stress the use of socioeconomic as well as ecological factors, and their model also considers factors such as spatial fishing effort, and avoids heavily fished areas whenever possible. The authors also emphasize that the model can generate a number of "solutions" based on varied weighting of socioeconomic and environmental parameters.

Table 2. List of goals and data requirements to parameterize a marine reserve design model

\begin{tabular}{|l|l|}
\hline \multicolumn{1}{|c|}{ Goals (identify target levels) } & \multicolumn{1}{c|}{ Parameters } \\
\hline Target \% of Each Habitat & Overall Species Diversity and Abundance Patterns \\
\hline Target \% of Critical Habitats & Target Species Diversity and Abundance Patterns \\
\hline Target \% of Rare Habitats & Bathymetry \\
\hline Target \% of Larval and Spawning Areas & Habitat Characterization \\
\hline $\begin{array}{l}\text { Connectivity Requirements for Larval } \\
\text { Dispersal }\end{array}$ & $\begin{array}{l}\text { Location of Larval/Nursery Grounds (target species } \\
\text { only?) }\end{array}$ \\
\hline & Fishing Pressure by Area \\
\hline & $\begin{array}{l}\text { Other Socioeconomic Conflict Areas } \\
\text { (manufacturing, etc) }\end{array}$ \\
\hline
\end{tabular}

Table 2 adapted from: Sala et al. 2002.

In contrast to multifaceted models like Sala et al. (2002), relatively simple traditional numerical models can predict single species response to the establishment of no-take reserves. Hastings and Botford (1999) use an equilibrium yield approach to analyzing no-take reserves against conventional fisheries restrictions; measuring the sustainable yield produced by a no-take reserve scenario against yield produced with a simple restriction on fishing effort. The authors conclude that for relatively sedentary species (e.g. invertebrates and reef fish), reserves can produce equivalent yield to traditional fisheries restrictions with significantly improved sustainability within the range of biological conditions used for the model. Indeed, after the closure of the scallop fishery on Georges Bank (off the coast of Massachusetts) became permanent in 1994, populations of scallops in the closed areas increased by more than an order of magnitude in the ensuing 5 years (Murawski et al., 2000). In northeaster coastal estuaries this model could be fit to Mercenaria mercenaria or other commercially-important shellfish species to determine the effectiveness of a proposed reserve. 
For reserves aiming to protect finfish, many models are available, however one of the simplest (and therefore broadly applicable) by Polacheck (1990) could be used in lieu of Hastings \& Botford (which assumes that all adults are sedentary) to provide an estimate of reserve size necessary to attain conservation and fisheries goals. Polacheck's model has been used in recent MPA related fisheries studies (e.g. Hilborn et al. 2004).

\subsection{Physical Oceanography}

It is also important to discuss the collection of physical oceanographic parameters in the context of reserve establishment. Circulation patterns are critical to larval dispersion, but complexity concerns often remove tide, current, and flow patterns from models. While all three authors cited above mention the importance of circulation, neither Polacheck (1990), Hastings \& Botford (1999), or Sala et al. (2002) incorporate flow into their models. Adequate techniques for the estimation of larval dispersal are becoming more widespread and available, and their application to MPA connectivity (e.g. Planes et al., 2008) should become standard practice in the citing process.

Failure to consider circulation and bathymetry, especially in a reserve designed to protect invertebrates (such as M. mercenaria) can cause failure of the reserve. Bene \& Tewfik (2003) examined the failure of a Turks \& Caicos no-take reserve to export biomass of Queen conch (Strombus gigas), and found that reserve placement was such that current patterns either retained larvae within the reserve or transported them to unsuitable settling grounds. Further, bathymetric features prevented migration of post-settlement $S$. gigas out of the reserve, resulting in severe density dependence within the reserve, and little to no increase in biomass outside the reserve.

\section{Ecosystem Response}

Once reserve goals are established, determining a list of parameters to monitor, and assessing change in these parameters, either compared to pre-establishment conditions, or compared to unprotected reference sites, is relatively straightforward. However, sufficient background and control data must be available to show that changes are the direct result of the reserve. Often the lack of replication necessitates the Before-After/Control-Impact or BACI experimental design in which a control and an experimental site are monitored both before and after a manipulation (such as removal of fishing pressure) to isolate the reserve effect (Osenberg et al, 2002).

\subsection{Single Metric Analyses}

The simplest way to examine the ecosystem-level effectiveness of no-take reserves is to identify a series of environmental parameters which are of concern in a given system and monitor for change Good baseline data permit both spatial and temporal changes to be detected. Many environmental monitoring variables have been suggested by the literature, including dissolved oxygen, chlorophyll, nutrients, turbidity, sediment chemistry, sediment contaminants, species richness and species diversity, among others (NRC, 2001; Jordan and Vaas, 2000; Meng et al., 2002). In addition, other variables may be selected based on the specific goals of the reserve. For instance, in the northeast the density of Zostera and/or 
Mercenaria or a target fish species could be suitable indicators of reserve success. The assertion that changes such as reduced hypoxia, higher diversity, and increased population levels of target species represent an "improvement" presumes one set of habitats, species, or conditions to be more "valuable" than another, and this assumption has been criticized as anthropocentric and as a value judgment (Noss, 2000; Link, 2002). However, the concept of restoring ecosystems must be centered on a set of human determined baseline conditions (Rudd, 2000). Preventing damage to ecosystems is preferable to relying on rehabilitation, but sometimes there is not a choice, so managers must use available tools to preserve ecosystems for future generations.

In addition to traditional sampling variables, quantitative analysis of benthic polychaete assemblages has been used extensively as a proxy for environmental change. Polychaetes are small size and sessile, and thus relatively easy to sample quantitatively (Elmgren, 1973). Polychaetes have been used as indicators of environmental conditions (Ellis, 2002; Calabretta and Oviatt, 2008), marine biodiversity (Olsgard et al., 2003), and anthropogenic impact (Giangrande et al., 2005; Pocklington and Wells, 1992), both outside and inside MPAs (Pinnegar et al., 2000; Giangrande et al., 2005). This group of annelid worms is used as an indicator of anthropogenic impact because it's members range from very sensitive to extremely tolerant, and can be found across a range of habitats from pristine to heavily disturbed (Pocklington and Wells, 1992; Calabretta and Oviatt, 2008) In addition to monitoring entire polychaete communities, it is also possible to use presence and abundance of one or a few polychaete indicator species as a proxy for ecosystem condition. In some northeastern US estuaries a sample indicator species could be Capitella capitata, a common threadworm found throughout soft bottom environments. C. capitata is an opportunistic species, and its abundance has been frequently correlated to high levels of anthropogenic impact such as bottom disturbance, eutrophication, etc. (Zajac and Whitlatch, 1982; Giangrande, 2005). In hard bottom environments, a number of species of syllid polychaetes have been shown to demonstrate similar properties (Giangrande et al., 2005).

\subsection{Multi-metric Analyses}

The concept of using a statistically weighted multi-metric index to reduce a large complex dataset into a single variable which represents ecosystem condition is clearly attractive. These multivariate indices are frequently referred to as Indices of Biotic Integrity (IBIs) although other similar acronyms are also used. If effective, an IBI allows for rapid quantitative analysis of ecosystem condition or restoration. An IBI is constructed by starting with a large list of measured parameters including many of the same variables discussed in section 3a. Parameter values are compared across a known gradient of anthropogenic impact using multiple regression to identify which parameters are positively (or negatively) correlated to habitats identified as pristine. The index is composed from the subset of the initial parameters which vary with impact, and weighted according to impact strength. The IBI can then detect spatial or temporal changes resulting from the no-take reserve. In an ideal situation, the IBI would increase not only inside the reserve, but also in adjacent areas, due to spillover and larval dispersal. 
IBIs have been used with considerable success in the tropics (e.g. Rodgers et al. 2010; Abessa et al., 2008), but have met with mixed results in temperate applications (Jordan and Vaas, 2002; Meng et al. 2002; Hughes et al, 2002). An IBI constructed for Narragansett Bay achieved moderate success, but was prone to occasionally diagnosing highly impacted sites as pristine (Meng et al., 2002). A comparison of the IBI approach to a more traditional multivariate ordination procedure in Chesapeake Bay found the traditional scheme to be more effective (Jordan and Vaas, 2002). In contrast, the Index of Estuarine Biotic Integrity (EBI) designed at the Ecosystems Center in Woods Hole MA., shows some level of effectiveness within New England and the Mid-Atlantic ecosystems (Hughes et al, 2002). Benthic multivariate indicators have also been used extensively in European waters, though a recent review (Van Hoey et al., 2010) still sites a gap in data availability and knowledge in terms of the use of multivariate indicators (a model is only as good as the data which parameterize it).

One major shortfall of an IBI is that it either assigns a positive or negative correlation to a variable, or excludes the variable entirely from the analysis. In this way, the use of an IBI has been compared to a measure of "ecosystem health" which has been criticized as both an oversimplification and anthropomorphism. Critics argue that insufficient research has been conducted to determine what parameters indicate a "healthy" ecosystem, and that unlike humans, who all have similar biological and chemical needs, a single metric cannot be applied across the wide range of habitats and species in an ecosystem (Link, 2002; Hearnshaw et al., 2002, Calicott, 1995). Thus, while IBIs show some promise as a useful tool, they must be used with caution.

\subsection{Interspecific Interactions and Habitat Change}

The study of ecosystem level interactions associated with no-take reserves is very complicated. In some cases, manipulations can help stabilize or restore an ecosystem to a desirable state. In other cases, human induced changes may not achieve desired goals and can have unexpected or undesirable side effects. The peer reviewed literature is ripe with examples of the latter, but a particularly written review paper by Carlos Duarte and colleagues (Duarte et al. 2009) provides a good starting point using the example of estuarine eutrophication and reversal to discuss the impact of 'shifting baselines'. Three key examples of 'shifting baselines' which are particularly applicable to the discussion of no-take marine reserves are trophic cascades, keystone interactions, and habitat change, all of which can potentially have both positive and negative impacts.

Interspecific interactions such as prey abundance, predation, and competition can often limit the ability of single species metrics to predict the response of a population to a change. Specific types of interactions often seen in no-take reserves are trophic cascades and keystone interactions. Trophic cascades can be defined as; "top-down controls resulting in conspicuous indirect effects two or three links distant from the primary response” (Frank et al., 2005). Top down controls are frequently observed in marine reserves since many reserves are established to protect large commercially viable fish species (e.g. Worm et al., 2009; Graham et al. 2011). These large fish are generally piscivorous, so a dramatic increase in their abundance can reduce abundance of their prey species, and this effect can "cascade" down the food chain 
(Ashworth \& Ormond, 2005; Pinnegar et al., 2000; Okey et al. 2004). While an increase of commercially viable fish is generally viewed as a positive response, it is important to carefully monitor at multiple trophic levels for unpredicted indirect effects which may affect the ability of the no-take reserve to accomplish its goals. The importance of these top down effects has been highlighted in several recent high profile papers suggesting the importance of no-take reserves as one part of a multifaceted approach to fisheries management (e.g. Worm et al., 2009; Beddington et al., 2007)

Similarly, keystone interactions occur when a change in the population of a particularly important "keystone" species causes disproportionate changes in all levels of the food web, either by direct or indirect effects. This change can sometimes cause a feedback loop which can cause reserves to function outside the range of expected results. McClanahan (2000) documented such an effect in no-take reserves in Kenya. Overfishing on these reefs had decimated populations of a large keystone predator, the triggerfish Balistapus undulatus which facilitated an explosion in the sea urchin population due to a release from predation. Full recovery of these reefs in the absence of fishing took much longer than expected because species diversity could not begin to recover until a sufficient $B$. undulatus population had built up to reduce urchin abundance.

Although comprehensive monitoring efforts, particularly monitoring of non-target fish and invertebrate species is perhaps the only way to detect the formation of an unexpected interspecific interactions, in many cases sufficient background data exists to predict the possibility of such an event. In such a case, it would be helpful to be able to generate a multispecies model to predict results of reserve establishment across trophic levels.

An excellent example of such a model is Ecopath (Christensen and Pauly, 1992). Ecopath is a mass continuity model that uses the constraints of mass balance to construct equations modeling flows of energy through a food web. Ecopath can be used to explore the long term ecological effects of fisheries, anthropogenic impacts, and even physical forces on various aspects of the biota (Christensen and Pauly, 1992; Okey et al., 2004; Ecopath, 2001). Recently, Ecopath has been expanded with the addition of two components. Ecosim and Ecospace, which allow the Ecopath parameters to vary with time and space respectively, and facilitate more detailed modeling (Ecopath, 2001). Ecospace is particularly powerful in an MPA context because it allows parameters to vary across different "habitats" in a spatial grid. This is ideal for modeling the boundaries of a synthetic no-take reserve (by changing fishing rate to zero for a specific group of cells), as well as to model the effects of different habitats (e.g., different proportions of critical habitat) on reserve effectiveness (Okey et al., 2004; Pitcher et al. 2002).

Habitat loss is one of the most dangerous threats to the success of reserves. Without proper habitat, species recovery can be difficult or impossible. While some research does suggest that reserves posess some capacity to help prevent habitat loss and restore damaged habitat (Graham et al. 2011; Sala et al., 2002; Palumbi, 2003), reserves cannot always protect against large-scale disturbances such as anthropogenic eutrophication and climate change. Jameson et al. (2002) argue that in many cases, trying to use a no-take reserve to meet management and 
conservation goals in the face of numerous atmospheric, terrestrial, and oceanic stressors is akin to building a submarine with screen doors. Jameson et al. point out that even with full protection, two thirds of reserves do not accomplish their habitat restoration and conservation goals, and that this trend is particularly evident in areas subject to high levels of stress through the three "screen doors" (i.e., atmospheric, terrestrial, and oceanic pollution). Jameson et al. (2002) suggest that reserve siting and monitoring must consider sources of external stressors to the system when determining reserve goals and deciding whether a no-take reserve will be an effective tool to meet conservation goals in an area. For example, in Narragansett Bay, Rhode Island, many areas of the upper bay which are subject to high anthropogenic nutrient loading from sewage and intensive watershed land usage are closed to fishing during all or part of the year (e.g. Hayes, 1992; RIDEM 2005). Whether a permanent closure of these areas would enhance fisheries management (by means of spillover or larval export) and/or meet other potential reserve goals such as improving recreational boating, swimming and tourism, is largely dependent on external factors; most notably the ability of management activity in the area (e.g. RIDEM, 2005; Deacutis, 2008) and the impact of climate change on the estuary (e.g. Melrose et al., 2009; Smith et al., 2010).

\section{Monitoring}

Throughout this paper, monitoring has been repeatedly referenced as a critical aspect of MPA study. Monitoring is essential to determining effectiveness, providing updates to stakeholders, and improving design through adaptive management. A well designed monitoring program should provide strong baseline data as well as regular data collection inside and outside the reserve. Long term monitoring of no-take reserves will further our understanding of reserve design, and the ecological and economic costs and benefits of reserves, provide better knowledge of the complex systems at work in the reserve and how anthropogenic activity affects them, and help to identify methods of developing effective tools to achieve specific marine conservation and management goals. (Pomeroy et al., 2005; NRC, 2001). This section addresses the science of monitoring reserves and provides guidelines for monitoring methods.

\subsection{General Monitoring Goals}

Just as reserves have specific goals, reserve monitoring programs must be goal oriented. Monitoring goals should be specific to the area and tied to the major stresses to the ecosystem and the reserve's goals. Monitoring efforts should focus on spatial and temporal shifts in four main categories: community composition; habitat maintenance and recovery; environmental degradation; and socioeconomic impacts (NRC, 2001). Monitoring sites must be comparable, representative, and well replicated (NRC, 2001; Polunin and Roberts, 1993). The monitoring program should be designed to answer the following questions: Does the reserve meet its goals? Are there any unanticipated consequences? Is reserve size and location optimal?

In order to eliminate as much variability as possible, it is important to use standardized sampling techniques, and cross-train sampling crews on sampling protocol, taxonomy, etc. (Pomeroy et al., 2005; Giangrande et al., 2005). This is particularly important when cross comparing monitoring data collected by different agencies. Taxonomy should be supplemented with molecular and genetic tools where available (Thorold et al., 2001; NRC, 
2001). As a 'rule of thumb', sampling resolution should be detailed enough to detect a change of $10-25 \%$ as statistically significant in order to distinguish reserve effects from masking factors such as long and short-term environmental changes and yearly recruitment variability (NRC, 2001; McClanahan, 1995; Halpern, 2003).

\subsection{Comprehensive Monitoring}

Pomeroy et al. (2005) present an extensive and comprehensive methodology for evaluating the effectiveness of MPAs, including steps for planning, monitoring, and evaluating a reserve's ability to meet ecosystem-level, fishery, and socioeconomic goals. Table 3 adapted from Pomeroy et al. (2005), represents a good model to follow for the northeast coastal zone.

Table 3. Lists of common reserve goals and experimental indicatorsa

\begin{tabular}{|l|l|}
\hline \multicolumn{1}{|c|}{ Reserve Goalsb } & \multicolumn{1}{c|}{ Indicators } \\
\hline 1. Marine resources sustained or protected & Focal species abundance $(1,3,6,7,8)$ \\
\hline 2. Biological diversity protected & Focal species population structure $(1,3,6,8)$ \\
\hline 3. Individual species protected & Habitat distribution and complexity $(1,2,4,5,7)$ \\
\hline 4. Habitat protected & Composition and structure of the community $(1,2,4,7)$ \\
\hline \multirow{2}{*}{ 5. Degraded areas restored } & Recruitment success within the community $(1,3,6,8)$ \\
\hline \multirow{2}{*}{$\begin{array}{l}\text { 6. Monetary benefits to society enhanced or } \\
\text { maintained }\end{array}$} & Food web integrity $(1,2,4)$ \\
\cline { 2 - 2 } 7. Non-monetary benefits to society enhanced or & Type, level, and return on fishing effort $(1,6,8)$ \\
\cline { 2 - 2 } maintained & Water quality $(1,4,7)$ \\
\hline \multirow{2}{*}{$\begin{array}{l}\text { 8. Restore/protect recreational and commercial } \\
\text { fisheries }\end{array}$} & Area showing signs of recovery $(1,2,4,5,6,7)$, \\
\cline { 2 - 2 } $\begin{array}{l}\text { while minimizing impact on fisheries yield and } \\
\text { CPUE. }\end{array}$ & Area under no or reduced human impact $(1,4,5,7)$ \\
\cline { 2 - 2 } & $\begin{array}{l}\text { Changes in conditions of ancestral and historical sites, } \\
\text { features, and/or monuments }(6,7)\end{array}$ \\
\hline
\end{tabular}

Table 3 adapted from Pomeroy et al. 2005. Left column lists common biological, physical, and social reserve goals applicable to NER. Right column lists useful experimental indicators in deciding if reserve goals have been met. Parenthesized numbers indicate reserve goals which can be monitored using the given indicator.

Many candidate areas for no-take reserves already have extensive monitoring plans in place, and often, it is desirable to make use of this existing effort, rather than devoting additional resources to collecting data that is already available. However, it is important to ensure compatibility between monitoring efforts. Monitoring goals may vary widely between agencies, so it is important to make sure that all of the monitoring goals of the specific reserve in question are being met by the monitoring plan. This is particularly important when combining data from multiple agencies, or adding supplemental stations to an existing dataset to improve spatial coverage. Subtle differences in sampling method can easily confound results, especially when trends are small. In order to assist with the standardization of sampling efforts, the North American MPA Network (NAMPAN) (www.cec.org/nampan) is currently working towards a co-operative monitoring program, which will standardize 
procedures across reserves.

\section{Fisheries}

The ability of no-take reserves to benefit fisheries is a widely discussed and debated aspect of the literature on MPAs. Reserve establishment procedures contain a great deal of socioeconomic consideration and stakeholder review processes. Removal of viable fishing grounds is often a very contentious proposal (e.g. Kalikosi and Vasconcellos, 2008), but if it could be demonstrated that a proposed MPA would accomplish its natural and cultural conservation goals and possibly benefit, or at least minimally impact fisheries, resistance to MPA establishment from fishers and fishing organizations, may be lessened (Ami et al, 2005; Delaney, 2003).

Opponents of MPAs argue that traditional fisheries management methods (e.g. catch limits, gear restrictions, etc.) are almost always more effective than closures (Roberts and Sargant, 2002; Shipp, 2002; Hanneson, 1998), and that spillover is negligible in most cases (Zeller and Russ, 1998; Shipp, 2002). Proponents argue that reserves produce bigger and more frequent trophy fish (Roberts et al., 2001), sacrifice little or no yield in exchange for increased sustainability (Polacheck, 1990), and can even increase yield for relatively sessile species in exploited fisheries (Hastings \& Botford, 1999; Okey et al, 2004; Russ \& Alcala, 1996). This argument is exacerbated by the complexity of interspecific interactions associated with marine fisheries and notorious difficulty associated in collecting large amounts of data on mobile finfish stocks. Many recent high profile review papers on global fisheries strike a middle ground, agreeing that no-take reserves are an important part of a holistic management strategy which includes reserves, catch shares, and traditional management methods (Worm et al., 2009; FAO, 2009).

The interspecific interactions discussed in section 3 are especially pertinent in a fisheries context. There is strong evidence that trophic cascades in reserves can affect fisheries sustainability (Pinnegar et al., 2000; Ashworth and Ormond, 2005; Frank et al., 2005). Further, evidence suggests that even after fishing pressure has been reduced, some heavily fished stocks do not recover. There are many hypotheses which explain these depensatory observations. The "cultivation" hypothesis, or trophic triangle predicts that adults of one species prey upon a second smaller species, but that adults of the second species, either consume or compete with juveniles of the first species. Thus, if the adult population of the first species is fished too heavily, survival of juveniles of that species will actually decrease, due to increased competition from the second species (Ursin, 1982; Walters and Kitchell, 2001). In addition, some evidence exists suggesting that the removal of top predators can cause a trophic cascade leading to a community shift, which lessens or removes the niche formerly occupied by the top predator, making recovery difficult (Frank et al., 2005).

\subsection{Recent Advances in Mark-Recapture}

Mark-recapture studies in fisheries management are far from new, and have been used extensively to estimate abundance, migration, and even mortality. The recent ability to supplement traditional mark-recapture protocols with advanced chemical and genetic 
techniques opens up a wide range of experimental options not previously explored. Soaking larval fish in a dye bath of alizerine or tetracycline causes the otolith of the larval fish to be permanently marked with a dye band. Recapture of these larvae post settlement can provide insight into larval growth rates, and dispersal rates, and can be used to estimate spillover from a reserve (Jones et al., 1999; Domeier, 2004; Forrester, 2002).

Recent advances in genetic and geochemical tracer signals hold a great deal of promise for use in temperate environments. It is becoming more and more feasible to identify individual genetic brood stocks of specific fish, either genetically, through mtDNA markers (Jones et al, 2005; Luzier \& Wilson, 2004), or through unique trace chemical markers on the otolith indicative of the natal region of the fish (Thorrold et al., 2001; Planes et al., 2009; Almany et al., 2007). Both techniques have shown promise in temperate waters and with migratory fish species, and have been applied in tropical reserves. As this technique continues to develop, it is becoming increasingly plausible to identify a unique signal associated with fish born inside a reserve, and in this way, estimate fish production resulting from spillover or larval dispersal from a reserve.

\section{Conclusions}

While no-take marine reserves are not the all-purpose solution for ecological restoration and conservation; they are a powerful tool, which, when placed properly, monitored effectively, and enforced successfully, can demonstrate positive results and help regulatory agencies accomplish both fisheries and natural resource related goals. To do so, however, the process must be grounded in science and driven by specific conservation or restoration goals, while also addressing socioeconomic impacts.

No-take reserves can be a single large area, or several smaller areas, representative of the diversity and species composition of the habitat being conserved, with a particular focus on the conservation of critical habitat- areas essential to the life cycle of species targeted for restoration (e.g. eelgrass). Reserves should be sited in a way that maximizes the ecological benefits, while minimizing socioeconomic liabilities. This can be done through a wide range of GIS and modeling related applications (Sholtz et al., 2004; Sala et al., 2002).

Studies to determine the ecosystem level effects of a no-take reserve must include detailed spatial and temporal monitoring efforts both inside and outside the reserve. Ecosystem response can be evaluated through the use of one or more single metric analyses, where a single variable (such as abundance of an indicator species) serves as a proxy for ecosystem response, or through multi-metric analyses, where a suite of variables are combined into a single index (IBI) which detects changes in ecosystem status. While the latter is a valuable method of synthesizing a large amount of data, IBI's should be used with caution as they have met with mixed success in the northeast US (Meng et al., 2002; Jordan and Vaas, 2002).

The use of no-take reserves as a fisheries tool is heavily debated, and can be extremely contentious. Models predict that no-take reserves function best at protecting heavily exploited site associated or sedentary stocks, and that no-take reserves are capable, under the right conditions, of producing equivalent or slightly higher yields than traditional effort restriction 
methods, which much higher levels of sustainability (Russ and Alcala, 1996; Hastings and Botford, 1999). Mobile pelagic fish stocks are difficult to effectively protect using no-take reserves, unless reserves are used to protect habitats critical to the stock, such as breeding or nursery grounds. Predicting the fisheries impact of a no-take reserve is often complicated by interspecific interactions, such as trophic cascades, trophic triangles, and keystone interactions (Ashworth and Ormond, 2005; Pinnegar et al., 2000; Ursin, 1982). Recent advances in mark-recapture methods including larval marking and otolith chemical tracer analysis may help scientists shed additional light on the fisheries effects of no-take reserves.

\section{Acknowledgement}

This work was made possible and funded by an NSF IGERT program grant\# 0504103 to the University of Rhode Island Coastal Institute. Thanks to Dr. Charles Roman with NPS for hosting my IGERT white paper internship, and for all of his help with this project. I would also like to thank Dr. Candace Oviatt, Dr. Judith Swift, and anonymous reviewers for their thoughtful comments on this manuscript. Thanks are also due to Kate Smukler with NOAA's MPA center, Cliff McCreedy and Gary Davis with NPS, and Rob Brumbaugh with TNC.

\section{References}

Abessa, D.M.S., R.S. Carr, E.C.P.M. Sousa, B.R.F. Rachid, L.P. Zaroni, Y.A. Pinto, M.R. Gasparro, M.C. Bícego, M.A. Hortellani, J.E. Sarkis, \& P.M. Maciel. (2008). Integrative ecotoxicological assessment of a complex tropical estuarine system. In: T.N. Hoffer, Editor, Marine Pollution: New Research, Nova Science Publishers, Inc., New York, USA, pp. 1-36

Almany, G. R., M. L. Berumen, S. R. Thorrold, S. Planes, \& G. P. Jones. (2007). Local Replenishment of Coral Reef Fish Populations in a Marine Reserve. Science 316:742-744.

Altabet, M., \& Varekamp, J. (2006). Mechanisms of Eutrophication Related 15N Enrichment in Long Island Sound. Prec. $8^{\text {th }}$ LISF/NEERS conference. New London, CT. (Oct 26, 2006)

Ami, D., Cartigny, P., \& Rappaport, A. (2005). Can Marine Protected areas Increase both Economic and Biological Situations? C.R. Biologies 328:357-66.

Ashworth, J., \& R. Ormond. (2005). Effects of Fishing Pressure and Trophic Group on Abundance and Spillover Across Boundaries of a No-Take Zone. Biological Conservation 121:333-344.

Beddington, J. R., D. J. Agnew, \& C. W. Clark. (2007). Current Problems in the Management of Marine Fisheries. Science 316:1713-1716.

Bene, C., \& A. Tewfik. (2003). Biological Evaluation of Marine Protected Area: Evidence of Crowding Effect on a Protected Population of Queen Conch in the Caribbean. Marine Ecology 24(1):45-58.

Bohnsack, J. (2006). Marine Reserves. They Enhance Fisheries, Reduce Conflicts, and Protect Resources. Woods Hole Oceanographic Institution. Ocean Life Institute. [Online] Available: http://www.whoi.edu/institutes/OLI/currenttopics/ct_mpa_marine_reserves.htm 
Bradley, M., \& Stolt, M. (2006). Landscape-level seagrass-sediment relations in a coastal lagoon. Aquatic Botany 84(2):121-128.

Calabretta, C. J., \& C. A. Oviatt. (2008). The response of benthic macrofauna to anthropogenic stress in Narragansett Bay, Rhode Island: A review of human stressors and assessment of community conditions. Marine Pollution Bulletin, 56:1680-1695.

Chape, S., J. Harrison, M. Spalding, \& I. Lysenko. (2005). Measuring the extent and effectiveness of protected areas as an indicator for meeting global biodiversity targets. Philosophical Transactions of the Royal Society B: Biological Sciences, 360:443-455.

Christensen, V., \& D. Pauly. (1992). ECOPATH II--A software for balancing steady-state ecosystem models and calculating network characteristics. Ecological Modelling, 61 (3-4):169-185.

Cote, I., I, Mosquiera, \& J. Reynolds. (2001). Effects of marine reserve characteristics on the protection of dish populations: a meta analysis. Journal of Fish Biology, 59:178-189.

Cowie-Haskell, B., \& J. Delaney. 2003. Integrating Science into the Design of the Tortugas Ecological Reserve. MTS Journal, 37(1):68-79.

Dalton, T. R. Thompson, \& D. Jin. (2010). Mapping human dimensions in marine spatial planning and management: An example from Narragansett Bay, Rhode Island. Marine Policy, 34:309-319.

Deacutis, C. F. (2008). Evidence of Ecological Impacts from Excess Nutrients in Upper Narragansett Bay. Pages 349-381 in A. Desbonnet and B. Costa-Pierce, editors. Science for Ecosystem-based Management. Springer, New York.

Degraer, S., G. Moerkerke, M. Rabaut, G. Van Hoey, I. Du Four, M. Vincx, J.-P. Henriet, \& V. Van Lancker. (2008). Very-high resolution side-scan sonar mapping of biogenic reefs of the tube-worm Lanice conchilega. Remote Sensing of Environment, 112:3323-3328.

Delaney, J. (2003). Community capacity building in the designation of the Tortugas Ecological Reserve. Gulf and Caribbean Research, 14(2):163-169.

Dennison, W., R. Orth, K. Moore, J. Stevenson, V. Carter, S. Kollar, P. Bergstrom, \& R. Batiuk. (1993). Assessing water quality with submersed aquatic vegetation. Habitat requirements as barometers of Chesapeake Bay health. Bioscience, 43:86-94.

Domeier, M. (2004). A potential larval recruitment pathway originating from a Florida marine protected area. Fisheries Oceanography, 13(5):287-294.

Duarte, C., D. Conley, J. Carstensen, \& M. Sánchez-Camacho. 2009. Return to "Neverland" Shifting Baselines Affect Eutrophication Restoration Targets. Estuaries and Coasts, 32:29-36.

Ecopath (2001). The Ecopath with Ecosim (EwE). [Online] Available: http://www.ecopath.org/index.php?name=About\&sub=Aboutewe

Ellis, G. (2002). An Examination of the Benthic Macrofauna of Narragansett Bay and the 
Possible Implications of Winter-Spring Bloom Intensity on Population Size. Masters Thesis, University of Rhode Island.

Elmgren, R. (1973). Methods of Sampling Soft Bottom Meiofauna. OIKOS Supplementum, 15:115-120.

FAO. (2009). The state of world fisheries and aquaculture. Food and Agriculture Organization of the United Nations., Rome.

Federal Register. (2000). Presidential Documents. Executive Order 13158 of May 26, 2000. 65(105). May 31, 2000. Washington, DC: U.S. Government Printing Office. [Online] Available: http://www.mpa.gov/information_tools

Frank, K., B. Petrie, \& J. Choi, W. Leggett. (2005). Trophic Cascades in a formerly Cod Dominated Ecosystem. Science, 308:1621-1623.

Friedlander, A. M., E. K. Brown, \& M. E. Monaco. (2007). Coupling Ecology and GIS to Evaluate Efficacy of Marine Protected Areas in Hawaii. Ecological Applications, 17:715-730.

Fujita, Rod. (2003). Heal the Ocean: Solutions for Saving our Seas. 227pp. Vancouver, BC, Canada: New Society Publishers.

Giangrande, A., A. Delos, L. Musco, M. Licciano, \& C. Pierri. (2004). Polychaete assemblages of rocky shore along the South Adriatic coast (Mediterranean Sea). Cahiers de Biologie Marine, 45:85-95.

Giangrande, A., M. Licciano, \& L. Musco. (2005). Polychaetes as environmental indicators revisited. Marine Pollution Bulletin, 50(11):1153-62.

Graham, N., T. Ainsworth, A. Baird, N. Ban, L. Bay, J. Cinner, D. DeFreitas, G. Diaz-Pulido, M. Dornelias, S. Dunn, P. Feidelman, S. Foret, T. Good, J. Kool, J. Malella, L. Pennin, M. Pratchett, \& D. Williamson. (2011). From Microbes to People: Tractable Benefits of No-Take Areas for Coral Reefs. Oceanography and Marine Biology: An Annual Review, 49:105-136.

Halpern, B. (2003). The Impact of Marine Reserves: Do Reserves Work, and Does Reserve Size Matter? Ecological Applications, 13(1):117-137.

Halpern, B., \& R. Warner. (2003). Matching marine reserve design to reserve objectives. Proceedings of the Royal Society of London, 270:1871-1878.

Hannesson, R. (1998). Marine Reserves: What would they Accomplish? Marine Resource Economics, 13(3):1-16.

Hastings, A., \& L. Botsford. (1999). Equivalence in yield from marine reserves and traditional fisheries management. Science, 284:1537-1538.

Hayes, K. M. (1992). Estimating the benefits of water quality improvements in the Upper Narragansett Bay. Marine resource economics 7:75.

Hearnshaw, E., R. Cullen, \& K. Hughey. (2002). Ecosystem health demystified: An 
ecological concept determined by economic means. 30pp. [Online] Available: http://een.anu.edu.au/e05prpap/hearnshaw.doc.

Henn, R., \& S. Cullen. (2004). The Fire Island inlet to Montauk Point reformulation study and coastal restoration opportunities. USACE/TNC Conference. [Online] Available: http://www.hec.usace.army.mil.

Hilborn, R., K. Stokes, J. Maguire, T. Smith, L. Botsford, M. Mangel, J. Orensanz, A. Parma, J. Rice, J. Bell, K. Cochrane, S. Garcia, S. Hall, G. Kirkwood, K. Sainsbury, \& G. Stefansson, C. Walters. (2004). When can marine reserves improve fisheries management. Ocean \& Coastal Management, 47:197-205.

Hughes, Jeffrey, Linda A. Deegan, Melissa J. Weaver, \& Joseph E. Costa (2002). Regional Application of an Index of Estuarine Biotic Integrity Based on Fish Communities. Estuaries, 25(2):250-263.

Jameson S., M. Tupper, \& J. Ridley. (2002). The three screen doors: can marine "protected” areas be effective? Marine Pollution Bulletin, 44(11):1177-1183.

Jennings, S., \& N. Polunin. (1997). Impacts of predator depletion by fishing on the biomass and diversity of non-target reef fish communities. Coral Reefs, 16(2):71-82.

Jones, G., M. Milicich, M. Emslie, \& C. Lunow. (1999). Self-recruitment in a coral reef fish population. Nature, 402(16):802-803.

Jones, G., S. Planes, \& S. Thorrold. (2005). Coral Reef Fish Larvae Settle Close to Home. Current Biology, 15:1314-1318.

Jordan, S., \& P. Vaas. An index of ecosystem integrity for Northern Chesapeake Bay. Environmental Science \& Policy, 3(1):59-88.

Kalikosi, D., \& M. Vasconcellos. (2008). Marine Protected Areas and Reconciling Fisheries with Conservation: Insights from the Common Property Theory. Proceedings of the Fourth World Fisheries Congress, 49(2). pp. 1211-1219. American Fisheries Society Symposium.

Link, J. (2002). What does Ecosystem Based Fisheries Management Mean? Fisheries, 27(4):18-21.

Luzier, C., \& R. Wilson Jr. (2004). Analysis of mtDNA haplotypes of kelp bass tests for sibling-dominated recruitment near marine protected areas of the California Channel Islands. Marine Ecology Progress Series, 277:221-230.

McClanahan, T. (1995). A coral reef ecosystem-fisheries model: Impacts of fishing intensity and catch selection on reef structure and process. Ecological Modeling, 80:1-19.

McClanahan, T. (2000). Recovery of a coral reef keystone predator, Balistapus undulatus, in East African marine parks. Biological Conservation, 94:191-198

Melrose, D. C., M. S. Berman, L. M. Smith, \& C. A. Oviatt. (2009). The ecological effects of climate change on the Narragansett Bay estuary.in ICES, Berlin, Germany. 
Meng, L., C. Orphanides, \& J. Powell. (2002). Use of a Fish Index to Assess Habitat Quality in Narragansett Bay, Rhode Island. Transactions of the American Fisheries Society 131:731-742.

Murawski, S. A., R. Brown, H. L. Lai, P. J. Rago, \& L. Hendrickson. (2000). Large-scale closed areas as a fishery-management tool in temperate marine systems: the Georges Bank experience. Bulletin of Marine Science, 66:775-798.

National Research Council (NRC), Committee on the Evaluation, Design, and Monitoring of Marine Reserves and Protected Areas in the United States, Ocean Studies Board, and Commission on Geosciences, Environment, and Resources. (2001). Marine protected areas: Tools for sustaining ocean ecosystems. 272pp. Washington, D.C.: National Academy Press.

Noss, R. (2000). Sustaining Ecological Integrity. Global Bioethics., 12:11-19

Okey, T., et al. (2004). A trophic model of a Galápagos subtidal rocky reef for evaluating fisheries and conservation strategies. Ecological Modeling, 172:383-401.

Olsgard, F., T. Brattegard, \& T. Holthe. (2003). Polychaetes as surrogates for marine biodiversity: lower taxonomic resolution and indicator groups. Biodiversity and Conservation, 12:1033-1049.

Osenberg, C., C. St. Mary, J. Wilson, \& W. Lindberg. (2002). A quantitative framework to evaluate the attraction-production controversy. ICES Journal of Marine Science, 59:214-221.

Palumbi, S. (2002). Marine Reserves: A Tool for Ecosystem Management and Conservation. In Pew Oceans Commission Report 40pp. Arlington, VA: Pew Ocean Commission.

Pinnegar, J., et al. (2000). Trophic cascades in benthic marine ecosystems: lessons for fisheries and protected area management. Environmental Conservation, 27(2):179-200.

Pitcher, T., E. Buchary, \& T. Hutton. (2002). Forecasting the benefits of no-take human-made reefs using spatial ecosystem simulation. ICES Journal of Marine Science, 59:17-26.

Planes, S., G. P. Jones, \& S. R. Thorrold. (2009). Larval dispersal connects fish populations in a network of marine protected areas. Proceedings of the National Academy of Sciences, 106:5693-5697.

Pocklington, P., \& P. Wells. (1992). Polychaetes: key taxa for marine environmental quality monitoring. Marine Pollution Bulletin, 24:593-598.

Polacheck, T. (1990).Year around closed areas as a management tool. Natural Resource Modeling, 4(3):327-53.

Polunin, N., \& C. Roberts. (1993). Greater biomass and value of target coral reef fishes in two small Caribbean marine reserves. Marine Ecology Progress Series, 100:167-176.

RIDEM. (2005). Plan for Managing Nutrient Loadings to Rhode Island Waters. RI General Law § 46-12-3(25).

Roberts, C., \& H. Sargant. (2002). Fisheries benefits of fully protected marine reserves: why 
habitat and behavior are important. Natural Resource Modeling, 15(4):487-507.

Roberts, C., J. Bohnsack, F. Gell, J. Hawkins, \& R. Goodridge. (2001). Effects of Marine Reserves on Adjacent Fisheries. Science, 294:1920-1923.

Rodgers, K. u. S., P. L. Jokiel, C. E. Bird, \& E. K. Brown. (2010). Quantifying the condition of Hawaiian coral reefs. Aquatic Conservation: Marine and Freshwater Ecosystems, 20:93-105.

Rudd, M. (2000). Live long and prosper: collective action, social capital and social vision. Ecological Economics, 34 (234): 131-144.

Russ, G., \& A. Alcala. (1989). Effects of intense fishing pressure on an assemblage of coral reef fishes. Marine Ecology Progress Series, 56:13-28.

Russ, G., \& A. Alcala. (1996). Marine Reserves: Patterns of recovery and decline of large predatory fish. Ecological Applications, 6(3):947-961.

Scholz, A., K. Bonzon, R. Fujita, N. Benjamin, N. Woodling, P. Black, \& C. Steinback (2004). Participatory Socioeconomic Analysis: Drawing on Fishermen's Knowledge for Marine Protected Area Planning in California. Marine Policy, 28(4):335-349.

Schubel, J, T. Bell, \& H. Carter eds. (1991). The Great South Bay. 107pp. Albany, NY: SUNY publishing.

Shipp, R. (2002). No Take Marine Protected Areas (nMPAs) as a fishery management tool, a pragmatic perspective. A Report to the FishAmerica Foundation. [Online] Available: http://www.asafishing.org/asa/images/government/gais_shipp.pdf.

Smith, L. M., S. Whitehouse, \& C. A. Oviatt. (2010). Impacts of Climate Change on Narragansett Bay. Northeastern Naturalist, 17:77-90.

Stachowitz, J., R. Whitlatch, \& R. Osman. (1999). Species diversity and invasion resistance in a marine ecosystem. Science, 286:1577-79.

Stevens, S., B. Milstead, M. Albert, \& G. Entsminger. (2005). Northeast Coastal and Barrier Network Vital Signs Monitoring Plan. Technical Report NPS/NER/NRTR--2005/025. 134pp. Boston, MA. National Park Service/Department of Interior, Northeast Region.

Thorrold, S., C. Latkoczy, P. Swart, \& C. Jones. (2001). Natal Homing in a Marine Fish Metapopulation. Science, 291:297-299.

Ursin, E. (1982). Stability and variability in the marine ecosystem. Dana, 2:51-65.

Van Hoey, G., A. Borja, S. Birchenough, L. Buhl-Mortensen, S. Degraer, D. Fleischer, F. Kerckhof, P. Magni, I. Muxika, H. Reiss, A. Schröder, \& M. L. Zettler. (2010). The use of benthic indicators in Europe: From the Water Framework Directive to the Marine Strategy Framework Directive. Marine Pollution Bulletin, 60:2187-2196.

Walters, C., \& J. Kitchell. (2001). Cultivation/depensation effects on juvenile survival and recruitment: implications for the theory of fishing. Can. J. Fish. Aquat. Sci. 58: 39-50 


\section{Macrothink}

Worm, B., R. Hilborn, J. K. Baum, T. A. Branch, J. S. Collie, C. Costello, M. J. Fogarty, E. A. Fulton, J. A. Hutchings, S. Jennings, O. P. Jensen, H. K. Lotze, P. M. Mace, T. R. McClanahan, C. Minto, S. R. Palumbi, A. M. Parma, D. Ricard, A. A. Rosenberg, R. Watson, \& D. Zeller. (2009). Rebuilding Global Fisheries. Science, 325:578-585.

Zajac, R., \& R. Whitlatch. (1982). Response of estuarine infauna to disturbance. II. Spatial and temporal variation of succession. Marine Ecology Progress Series, 10:15-27.

Zeller, D., \& G. Russ. (1998). Marine reserves: patterns of adult movement of the coral trout (Plectropomus leopardus (Serranidae)). Can. J. Fish. Aquat. Sci. 55:917-924.

\section{Copyright Disclaimer}

Copyright reserved by the author(s).

This article is an open-access article distributed under the terms and conditions of the Creative Commons Attribution license (http://creativecommons.org/licenses/by/3.0/). 